\title{
The Use of Cloud Technologies in the Modern Educational Process
}

\author{
Natalia P. Nikonova, Larisa N. Gorina, Linar G. Akhmetov
}

\begin{abstract}
The article describes the features of the use of blog technologies in the educational field. The relevance of the article is to study the influence of computer technologies on the process of computerization of education, which is accompanied by the introduction of corrections to the content of learning technologies due to significant changes in the pedagogical theory and practice of the educational process. The purpose of the article is to study the process of forming the professional competence of students through the use of such Internet technologies as a blog. Attention is focused on the problem of determining this Internet technology and its essence in the educational process. The article also highlighted a number of stable characteristics of blogs and described the functions performed by blogs.
\end{abstract}

Index Terms: cloud technologies, blog, professional competence, blog, informatization, communication

\section{INTRODUCTION}

The relevance of this article lies in the fact that, firstly, Internet technologies as a teaching tool provide students with additional powerful motivation: they have the opportunity to use their knowledge and formed skills almost immediately and more efficiently than it happens only during educational communication. Secondly, students learn to efficiently extract (use) information from electronic texts posted on the Internet, as a rule, they have more relevant content than texts on paper. For the educational process, cloud technologies have created a deep breakthrough and have realized subject-object relations between teachers and students on the Internet, as well as the exchange of experience between teachers, feedback from students and the like.

Many modern researchers were engaged in this problem. However, most of the presented studies do not sufficiently reflect the general nature of the application of cloud technologies in the educational process.

Albekova Z.M., Alzhanova D.I., Kanev M.A., Kapustina D.D., Potanina M.V., Sirotkin A.Yu. consider e-education systems and cloud technologies in education

Revised Manuscript Received on July 09, 2019.

Natalia P. Nikonova, Tyumen Industrial University, Russia

Larisa N. Gorina, Togliatti State University, Russia

Linar G. Akhmetov, Kazan Federal University, Russia and their advantages. However, these researchers did not fully reflect the role of cloud technologies in relation to education.

Anokhina E.V., Godina E.Z., Matukhin P.G., Provotorova E.A., Titova E.P. suggest using cloud technologies for distant study of the "human anatomy" course for foreign medical students at the pre-university level of study.

Such researchers as Berstneva S.V., Klyueva MS, Oskin D.N., Shekerbekova Sh.T., Nesipkaliev U. suggest using cloud technologies in additional professional education, which expands the sphere of application of cloud technologies in education.

Shangina E.I., Shangin G.A. consider this issue from the standpoint of mobile-cloud technologies in modern education, which allows students to be always in touch and up to date with new tasks and topics for study.

Bobrova I.I., Karaskova N.S., Soldatenkov R.M., Yaganova A.A., Lozitsky V.L. they consider the issues of intellectual socialization of subjects of vocational education using cloud computing technologies, as well as the development of the information society

Krupoderova K. R., Kurganskaya G.S. use cloud technologies in the formation of the competencies of bachelors of vocational education, which makes it possible to expand the use of cloud technologies in education.

\section{METHODOLOGY}

When studying the problems of the use of cloud technologies in education, such general scientific methods as the method of analysis and synthesis were widely used, which made it possible to better present certain aspects of this problem and then differently combine them in accordance with the requirements of the time.

The method of synergistic analysis allowed to reveal the essence of the organizational aspects of cloud technologies, which are able not only to solve private tasks of individual spheres of society, but also to act as the organizing force of the new information society.

The use of the comparative historical method allows us to trace the patterns of development of the application of cloud technologies in education, which provides a connection with a specific historical environment and 


\section{The Use of Cloud Technologies in the Modern Educational Process}

keeps the practical importance of cloud technologies in the required application.

The application of the method of systematization and classification allowed in a more concise form to reveal the main aspects of the topic being studied and draw conclusions.

\section{RESULTS}

The results of this article can be applied in further theoretical study of cloud technologies. The use of data on the use of cloud technologies in the development of the information society will expand the understanding of the field of education in general and the specific tasks facing education in particular.

Practical applicability is the use of cloud technologies in school education, as well as in higher and secondary vocational education. Applying the results of this article will allow us to better understand the role of cloud technologies in the educational process.

Cloud technologies (eng. Cloud technologies) is a new service that allows you to remotely use data processing and storage facilities.

Cloud pedagogical technologies provide the use of Internet services as a means of interactive learning without the use of local software, except for the browser and plug-ins to it. "One of the tasks of a modern teacher in this education system is to navigate in the latest electronic developments and direct its students to use the most qualitative and useful resources" [12].

Cloud technologies provide the implementation of many types of educational activities, monitoring and evaluation of students' educational achievements, on-line testing, openness of the educational environment.

The use of cloud technologies in the educational process of general educational institutions will primarily solve the problem of ensuring equal access of students and teachers to high-quality educational resources both in the classroom and during extracurricular time. "Information technology today is an integral part of our life. Without them, none of the spheres of society is unthinkable, and education is no exception. Cloud technologies play a significant role among various information technologies used in education "[8].

Application of Internet capabilities in educational practice is a new effective tool for intensifying the educational process, a tool for transforming the teaching of various disciplines into a creative process of cooperation between the teacher and students in achieving a common goal: continuously improve their knowledge while doing what they are interested in doing. "Cloud technologies are used in all industries where high performance and fast access to resources and services are required, and the educational environment is no exception" [2].

Such Internet resources as blogs have a great potential in the development of two types of educational activities at once, namely, reading and comprehension (learning). Characteristic of blogs are short entries of temporary significance.

New teaching methods provide educational opportunities using modern hardware and software - laptops, wireless

systems and virtual learning environments. Currently, in the educational process, you can use online diaries, that is, blogs. The use of blogs is very useful, they enable students to reflect on the material being studied and present their understanding, and the possibility of posting comments on posts to blogs contributes to obtaining feedback and potential support for new ideas.

The possibility of including hyperlinks to other resources in the text will help students to understand the relationships and context of knowledge, their construction and development. Blog becomes a virtual space for testing new concepts. The blog hyperlink provides readers with a broader context for a particular message on the Internet, attracting news, images and other information. In addition, the blog information is updated frequently.

In the era of the so-called "new" pedagogy, students should independently master new knowledge and concepts, i.e. cultivate and engage in self-study.

In this way, blogs will provide students with the opportunity to manage their studies, publish their own thoughts and demonstrate an understanding of the material. "The use of cloud technologies implies distributed and remote processing and storage of data. The user is provided with a place for his files and round-the-clock access to them via the Internet This is one of the key advantages of cloud services, since data access can be from any computer or other device connected to the Internet "[4; P.71].

Blogs effectively satisfy a person's need for self-expression, public expression of one's own point of view, communication with people who have similar interests.

The extraordinary popularity of blogs is due to two main circumstances: first, publishing on the Internet using blogs is incredibly easy - in fact, creating a new post is reduced to typing its text in a web form and sending it to the server by pressing the "Publish" button and the second reason is instant online availability of published information.

Blogs in teaching practice can be viewed as:

1. Platform for pedagogical discussions. The network diary can serve as an open or closed environment for organizing pedagogical discussions. To discuss the organization of online educational projects using social software.

2. Ability to consult and obtain additional knowledge.

3. Platform for the organization of training students for basic and supplementary courses.

4. Platform for organizing a distance learning course. The blog may publish lecture posts, ask questions and go through discussions. At the same time, course participants can work in a virtual learning environment, and this can be very useful for both teachers and students.

5. Environment for the organization of network research activities of students. Working in a joint study (project), students can show their results on their blog or on the teacher.

Blogs have great potential for active and interactive learning, intensive interaction between students and teachers, the development of higher-order thinking skills and greater flexibility of the educational process. Blogs allow students to use various ways of personal and intellectual development of new concepts in the process of visualizing abstract ideas and interactive interaction. 
Blogs provide students with the opportunity to manage their learning, publish their own thoughts and demonstrate an understanding of the material, provide the possibility of individualizing the content of training. they can be used in teaching any discipline to students of all ages; they can read and write. Blogs can not only serve as a means of organizing the process of learning and communication between teachers and students, but also provide students with the opportunity to share their thoughts or additional materials with the class. In order to effectively use blogs in the learning process should follow the following recommendations:

- first, the teacher must visit the blogs created by other teachers in order to form an idea of how they can be used in the educational process;

- secondly, the teacher must create his own blog in order to have an idea about their functions and possibilities in practice;

- thirdly, before offering such a tool for teaching students, it is necessary to simulate a blog for their students (development of rules, discussion of topics, preliminary preparation of materials);

- Fourthly, blogs need to be popularized, so that the process of discussion and communication with experts takes place.

"Cloud technology is a new way of organizing the educational process and offers an alternative to the traditional methods of organizing the educational process; it creates an opportunity for personal learning, team teaching and interactive activities. The main advantage of using cloud technologies in education is not only reducing the cost of acquiring the necessary software, efficiency and improving the quality of the educational process, but also prepares pupils and students for life in a modern information society "[14; P.55].

The seven benefits of blogging for student learning should be noted:

1. Using blogs helps students become experts in the field of study. In the process of blogging can be divided into three stages: "search", "filtering" and "publication". In order to find information that can be used in an online diary (to comment, criticize, refer), the authors of blogs visit many sites on a specific topic.

2. The use of blogs enhances interest in the learning process. The motivating factor in learning is, firstly, the novelty of technology. Secondly, students write about what is important for them personally. They themselves manage the process of their learning by actively searching for information and receiving comments from other people.

3. The use of blogs gives students the right to participate in social processes, that is, they are included in the life of society. In the process of blogging, students quickly acquire certain knowledge, and not only teachers and fellow students can read their posts. Blogs take tasks out of the framework of the educational process and the teacher-student relationship, giving everyone the opportunity to evaluate and comment on their work. Publishing in blogs is a legitimate opportunity to communicate with a real audience.
4. The use of blogs opens up new opportunities for work in the classroom and abroad, since not all students have the opportunity to speak or be heard due to lack of time in the classroom and limited amount of training courses in the traditional organization of training. And blogging will allow each student to take part in the discussion, with their help the group goes beyond its physical boundaries and expands to an endless international audience, which gives an opportunity to get an idea of how the published information is perceived by representatives of the "outside world".

5. The use of blogs actualizes education, as it provides ample opportunities for the selection of educational material not only in printing publications, but also in electronic ones. In addition, it makes it possible to drastically reduce the time taken to introduce scientific facts and discoveries into academic discipline. "Replacing traditional teaching tools is didactically justified only if the electronic teaching tools used in the ICT training session (in our case, training tools hosted in the clouds and provided by cloud services) are an order of magnitude more efficient due to their technological and didactic potential. At the same time, we must not forget that the hypertrophied absolutization of the role of information and communication technologies is destructive for live interpersonal communication between the trainer and the learners, which is transferred exclusively to the virtual electronic field. It is impossible not to take into account the danger of computer dependence noted by psychologists. Cases of incorrect academic behavior of students armed with the latest technological advances in the field of ICT are also frequent $[11 ;$ P.44].

6. The use of blogs actualizes learning outcomes. Due to the use of blogs in laboratory-practical classes and in independent work, it is possible to immediately apply the acquired knowledge for practical actions.

7. The use of blogs increases the legal and ethical awareness of students, since they must provide information in compliance with its copyright, they are responsible for the interpretation of the information presented. Students learn to separate reliable information from fictional information, and are required to do so in the correct form.

Advantages of blogs over other information technologies: - ease of use and accessibility: - the use of blogs does not require any special knowledge from the user, it allows the prompt publication of any information (text, graphics, audio and video files, animation, etc.);

- in blogs, user-friendly interface for reading and perception of information, customized by users according to their needs; - the use of special client programs that allow a convenient way to publish information both using a personal computer and using mobile communications (mobile phone, communicator, smartphone, etc.);

- the organization of the user's personal information space in the form of a diary or journal, which allows publishing, transmitting, processing, transmitting information of various kinds and contents and searching for it in the entire data array; 
- the ability to create communities that can be administered by several people with personal access settings for authors and commentators;

- Unified addressing system for messages and documents;

- The use of an automatic feedback mechanism allows you to exchange messages about the appearance on the blog of new information (comments) related to the prior notification, note, and the like;

- the ability for the user to simultaneously administer multiple blogs;

- Before any entry in the blog, you can add comments in the form of text, audio or video information, which are placed in the form of a hierarchical "tree";

- two-way exchange mail function, allows you to receive new messages and comments, as well as send answers and publish your messages;

- the use of a mechanism that makes it easy to keep track of new records of any number of users, as well as to regulate access to your own records. "Today, cloud technologies are a tool that every person uses almost every day. Services such as email, e-commerce, online games and other online entertainment are examples of common cloud technologies. Cloud technologies are gaining more and more popularity every day, they are rapidly developing and cover various areas of activity "'[7; P.95].

\section{CONCLUSION}

Thus, in order to effectively use blogs in the learning process, you should adhere to the following recommendations:s

first, the teacher should visit the blogs created by other teachers in order to form an idea of how they can be used in the educational process;

secondly, the teacher must create his own blog in order to have an idea about their functions and possibilities in practice;

thirdly, before offering such a tool for teaching students, it is necessary to simulate a blog for their students (development of rules, discussion of topics, preliminary preparation of materials);

fourth, blogs need to be popularized in order for the process of discussion and communication with experts to take place.

\section{REFERENCES}

1. Albekova Z.M. Electronic education systems and cloud technologies in education // Historical and socio-educational thought. 2016. No. S1. Pp. 6-8.

2. Alzhanova D.I. Advantages of using cloud technologies in education // Problems of modern science and education. 2016. № 3 (45). Pp. 75-77.

3. Anokhina E.V., Godina E.Z., Matukhin P.G., Provotorova E.A., Titova E.P. Online tools for information and methodological support of distant study of the course "human anatomy" for foreign medical students of the pre-university stage of education based on cloud byod-technologies microsoft onedrive / word-online // Bulletin of the Center for International Education of Moscow State University. Philology. Culturology. Pedagogy. The technique. 2015. No. 4. P. 33-39.

4. Berstneva S.V., Klyueva M.S., Oskin D.N. The use of cloud technologies in additional vocational education // Collected papers on the problems of additional vocational education. 2018. No. 35. P. 70-76.
5. Bobrova I.I. Study of the problem of intellectual socialization of subjects of vocational education using cloud computing technologies // Actual problems of modern science, technology and education. 2016. T. 1. S. 195-198.

6. Kanev M.A. The use of cloud technologies to improve the quality of education in higher education // Psychological, economic and managerial aspects of educational activities Materials of the correspondence scientific-practical conference. 2014. S. 98-100.

7. Kapustina DD, Potanina M.V. Features of the use of cloud technologies in education // World of Computer Technologies. Collection of articles of the All-Russian Student Scientific and Technical Conference. Scientific editor E.N. Mashchenko. 2018. pp. 93-95.

8. Karaskova N.S., Soldatenkov R.M. Application of cloud technologies in education on the example of microsoft office 365 // Bulletin of the Moscow State Regional University. Series: Physics and Mathematics. 2016. No. 1. P. 108-116.

9. Krupoderova K.R. Formation of competencies of bachelors of vocational education in the information environment based on cloud technologies // Problems of modern pedagogical education. 2016. № 51-6. Pp. 181-188.

10. Kurgan G.S. Self-organization of online education in cloud technologies // Bulletin of Buryat State University. 2014. № 9-3. Pp. 27-31.

11. Lozitsky V.L. Information and communication technologies in high school social and humanities education: didactic aspects of the use of cloud services // Higher School: Navukov-Metadichny and Public Chastopis. 2014. № 5 (103). Pp. 39-44.

12. Sirotkin A.Yu. Pedagogical potential of cloud technologies in higher education // Psychological and pedagogical journal Gaudeamus 2014. № 2 (24). Pp. 35-42.

13. Shangina E.I., Shangin G.A. Mobile-cloud technologies in modern education // International Research Journal. 2016. № 12-4 (54). Pp. 117-119.

14. Shekerbekova Sh.T., Nesipkaliev U. Opportunities for the introduction and use of cloud technologies in education // International Journal of Applied and Fundamental Research. 2015. № 6-1. Pp. 51-55.

15. Yaganova A.A. Cloud technologies in education as an element of the development of the information society // Bulletin of the RSUH. Series: Documentation and archival studies. Computer science. Information security and information security. 2016. № 1 (3). Pp 9-13.

16. Akhmetshin, E. M., Ilyina, I. A., Kulibanova, V. V., \& Teor, T. R. (2019). 'Employee engagement' management facilitates the recovery from crisis situations. Paper presented at the Proceedings of the 2019 IEEE Communication Strategies in Digital Society Seminar, ComSDS 2019, 50-55. doi:10.1109/COMSDS.2019.8709645

17. Ibatova, A. Z., \& Ippolitova, N. V. (2018). Structuring the content of disciplines in higher school using a block-modular rating system for future oil and gas engineers. International Journal of Civil Engineering and Technology, 9(3), 394-399.

18. Akhmetshin, E. M., Mueller, J. E., Chikunov, S. O., Fedchenko, E. A., \& Pronskaya, O. N. (2019). Innovative technologies in entrepreneurship education: The case of european and asian countries. Journal of Entrepreneurship Education, 22(1)

19. Bochkareva, T. N., Akhmetshin, E. M., Korotkova, A. L., Lyitkina, N L., Nasipov, I. S., \& Khaliullina, A. G. (2017). Research of students' cognitive activity. Espacios, 38(60)

20. Ibatova, A. Z., \& Ivanova, N. L. (2018). A professionally oriented approach to teaching engineering students: From theory to practice International Journal of Mechanical Engineering and Technology, 9(4), 977-982. 